\title{
Exploring the construct of task performance of academics in an Asian context
}

\section{Teaching is different from research}

\author{
Asif Ayub Kiyani \\ Faculty of Management and Human Resources, \\ National University of Sciences and Technology, Islamabad, Pakistan \\ Kartinah Ayupp \\ Faculty of Economics and Business, University of Malaysia Sarawak, \\ Kuching, Malaysia, and \\ Shahid Rasool \\ Department of Management Sciences, Iqra University, Karachi, Pakistan
}

\begin{abstract}
Purpose - The purpose of this paper is to explore the latent factorial structure of task performance and to establish its construct validity among academics working at private universities in Pakistan.

Design/methodology/approach - Through a cross-sectional research design, purposive sampling and quota sampling were used to allocate a sample of 347 academics from 21 private universities in the Punjab/ Islamabad Capital Territory of Pakistan. SPSS 20 and SmartPLS 2.0 software were used to perform exploratory factor and partial least squares analyses on the data.

Findings - The presence of two new constructs - student development performance and knowledge development performance - in the task performance of academics was confirmed in the private higher education industry in Pakistan.

Research limitations/implications - This research has extended the theory of task performance of academics conceptually based on the articulated and validated emergence of student development performance and knowledge development performance as two separate constructs.

Practical implications - This research extends the theory of academics' task performance conceptually, based on the articulation and validation of student development performance and knowledge development performance as two separate constructs. Moreover, the emergence of these two distinct constructs has practical implications in the education industry among Asian and western managers and employees.

Social implications - A two-factor solution that best fits the data has emerged from the researchers' observations. This contributes to the taxonomy of research in the domain of academics' task performance in the private higher education industry in Pakistan.

Originality/value - This study seeks to systematically and practically explore, for the first time, task performance within the context of Pakistan's private higher education industry. From the data analysis, the researchers were able to identify, establish and label two new latent constructs in academics' task performance.
\end{abstract}

Keywords Task performance, Exploratory factor analysis, Construct validity,

Knowledge development performance, Student development performance

Paper type Research paper

\section{Introduction}

Construct validity is an important measure for ensuring that results from research are of substantial value to the theoretical domain of any field of study (Johari et al., 2009). It helps to demonstrate the appropriateness and robustness of task performance construct. This study explores the construct validation of task performance among academics at private universities in Pakistan. The justification for this research is based on six important reasons: most studies in the Pakistani context consider only a few dimensions of academics' task performance (Siddiqui, 2005; Chughtai and Zafar, 2006; Rehman et al., 2009); these

Received 30 March 2016 Revised 18 August 2016 9 December 2016 20 March 2017 Accepted 22 March 2017 